\title{
The evolution of physical activity promotion. Are we entering a liquid age?
}

\author{
Karim Abu-Omar, Peter Gelius and Sven Messing
}

\begin{abstract}
In order to counteract risk factors for non-communicable diseases, promotion of physical activity has become increasingly relevant. This article outlines recent developments in this field, adopting a perspective based on Zygmunt Bauman's concepts of liquid modernity and liquid life. Five trends in physical activity promotion are identified: (Trend 1) The expansion of physical activity recommendations from a narrow focus on exercise to a broad concept of 24-h movement guidelines, (Trend 2) the increasing number of population groups targeted by these recommendations, (Trend 3) the ascent of efforts for physical activity promotion to the global level, (Trend 4) the emancipation of physical activity promotion from an add-on to a stand-alone public health topic, and (Trend 5) the ongoing conflict between sport, health and other sectors about the leading role in physical activity promotion. Based on these developments, physical activity might be classified as 'liquid' in Bauman's sense, that is, as being elusive and in a constant state of flux.
\end{abstract}

Keywords: public health, physical activity, health promotion

\section{Introduction}

\section{Physical activity and physical activity promotion}

Together with smoking, alcohol and unhealthy nutrition, physical inactivity is considered one of the major risk factors for a number of chronic conditions such as obesity, type- 2 diabetes and certain types of cancer (1). The new global World Health Organization (WHO) comparable estimates on physical activity (2) highlight the severity of physical inactivity as a public health issue. At the policy level, the recently published WHO Global Action Plan on Physical Activity 2018-2030 demonstrates that physical activity promotion is now being dealt with as an urgent public health issue at the highest levels (3).

Recommendations informing the population about adequate levels of physical activity (4) have arguably been the most widely visible instruments for making populations more active. Such recommendations are usually derived from clinically guided frameworks and concern the nature, duration, intensity, and volume of physical activity (5). They provide specific guidance on health-enhancing amounts and modalities of activity for individuals from different age groups, and with certain medical preconditions.

At the same time, physical inactivity has been the subject of substantial national and international policy development over the past decades (6), often based on guidelines for physical activity promotion and policy (3, 7-9). The underlying perspective of such guidelines differs substantially from that of physical activity recommendations for individuals: they address stakeholders such as practitioners, professionals, and political decision-makers; they recommend interventions for physical activity promotion; and their intention is to inform collective action and policymaking on how to promote physical activity among entire populations (5).

Friedrich-Alexander-Universität Erlangen-Nürnberg, Department of Sport Science and Sport, Erlangen, Germany.

Correspondence to: Karim Abu-Omar, Friedrich-Alexander-Universität Erlangen-Nürnberg, Department of Sport Science and Sport, Gebbertstraße 123b, Erlangen 91058, Germany. Email: karim.abu-omar@fau.de

(This manuscript was submitted on 4 March 2019 and received in revised form on 15 July 2019. Following blind peer review, it was accepted for publication on 6 September 2019)

Global Health Promotion 1757-9759; Vol 27(4): 15-23; 882381 Copyright () The Author(s) 2019, Reprints and permissions: http://www.sagepub.co.uk/journalsPermissions.nav DOI: 10.1177/1757975919882381 journals.sagepub.com/home/ghp 
Both individual recommendations for physical activity and guidelines for physical activity promotion have been revised and refined over time. In part, these modifications reflect the continuous emergence of new scientific evidence on physical activity. However, the ongoing development of guidelines may also be considered an indicator for the limited success of past physical activity promotion efforts (10). From a political science perspective, this is hardly surprising, as physical inactivity may be classified as a 'chronic policy problem' (11), the solution of which would be politically complex, involve multiple sectors and levels of government, and take more than government spending alone. Consequently, it is bound to keep reappearing on the political agenda.

Overall, while developments in individual physical activity recommendations are well-documented (12), the evolution of guidelines for physical activity promotion is far less clear. Additionally, it is uncertain how (if at all) advancements regarding these two types of document are connected, and what the potential end points of these developments could be. In order to answer such questions, it would be useful to develop an appropriate theoretical foundation to structure our observations. This article therefore aims to explore major trends in the development of physical activity recommendations and guidelines over the past decades using a theorybased approach that particularly draws on Zygmunt Bauman's concept of 'liquid modernity' $(13,14)$.

\section{Postmodern theory, liquid modernity, and physical activity}

Within the social sciences, reflections on the relationship between our postmodern age and individual health (behavior) have a tradition that goes back at least 30 years. For example, Glassner described in 1989 how 'the contemporary fitness mode incarnates, through practical beliefs and behavioral descriptions, some elemental premises and aspirations of a postmodern cultural order' (15).

The starting point of such reflections is postmodern society, which has been characterized among other things as being ephemeral, full of contradictions, anarchic (16), or even a 'juggernaut' (i.e. a runaway engine with so much power that it threatens to slip out of human control at any moment) (17). Bauman has contributed to this body of work by introducing the concepts of liquid modernity (13) and 'liquid life' (14). For Bauman, the metaphor 'liquid' signals that we live in a cultural age (the liquid modernity) that is in a constant state of flux, is elusive, and is governed by those who are rarely accountable for their actions (13). The result is a society that changes so fast that its non-ruling members are caught in a permanent struggle to stay afloat (thus living a liquid life), since they run the risk of drowning whenever they attempt to keep still (14).

For example, work and employment in liquid modernity can be described as having turned from solid to liquid states (13): today's labor markets offer more and more short-term, part-time, and minimum-wage jobs within a so-called 'gigeconomy.' Individuals are caught in these precarious employment conditions, facing uncertainty, harsh working conditions and dissolving boundaries between their work and private lives.

We propose that physical activity, as a public health issue, has also turned from 'solid' to liquid in the past decades, and that we may currently be entering a 'liquid age' of physical activity promotion. Based on this hypothesis, we have attempted to categorize recent developments in the field into major trends that fit the tenets of Bauman's basic approach. We employed the terminology by Rütten et al. (18), which is based on the three major types of evidence related to physical activity and health:

- Type I documents are based on evidence related to the health effects of physical activity. Recommendations describing the types, intensity and amounts of physical activity for individuals are good examples for this document type (19).

- Type II documents build on evidence for effective interventions to increase physical activity in individuals. A typical example is Interventions on Diet and Physical Activity: What Works by the WHO (20).

- Type III documents are based on evidence for effective policies to increase physical activity at the population level. An example is the EU's Council Recommendation on Health-Enhancing Physical Activity (HEPA) across Sectors (21).

From our perspective, tracking physical activity promotion over an extended period of time suggests 
that the scope of the field has constantly expanded, reaching more and more beyond health and sport into other sectors of society and policy. Using an inductive- and theory-based approach, we attempted to make sense of the observed developments and draw conclusions about their benefits and risks. In order to do so, we considered Bauman's general theory of social development a good basis on which to conceptualize the evolution in our field. As a result, we identified five major trends that describe the development of physical activity promotion from a solid to a liquid aggregate condition.

\section{Trend 1: expanding the concept of physical activity - from exercise to liquid physical activity}

The first, and arguably most obvious, trend in physical activity promotion over the past decades pertains to the dramatic expansion of the concept of physical activity itself. The documents corroborating this trend are predominantly related to Type I evidence on physical activity. Starting with the American College of Sports Medicine's (ACSM) Guidelines for Graded Exercise Testing and Exercise Prescription in 1975 (22) and the ACSM position statement in 1978 (23), public health began specifying the amount of physical activity people should engage in for optimal health benefits. A number of articles have described these early physical activity guidelines $(12,24,25)$.

ACSM's 1978 guidelines recommended exercise training on 3-5 days per week with an intensity equivalent to $60-90 \%$ of the maximum heart rate, and a duration of 15-60 min per session. Recommended activities included mostly sports and endurance pursuits such as running or jogging, swimming, skating, and bicycling. While walking and hiking were also listed as potential activities, the ACSM guidelines defined exercise as the standard through which health benefits could be achieved.

Beginning in the 1990s, a conceptual shift away from 'physical fitness' to HEPA took place. A major starting point was the publication of the new ACSM recommendations in 1995 that extended 'the traditional exercise-fitness model to a broader physical activity-health paradigm' (19). The focus of these recommendations shifted toward achieving general health and well-being that 'benefits health and functional capacity without undue harm or risk' (26), later referred to as HEPA. With this shift, physical activities such as walking and cycling for transport or household chores like general cleaning also became recognized as having beneficial health effects (19). In addition, the health effects of moderate-intensity (rather than only vigorous) activity were now also acknowledged.

More recently, since about 2010, the concept of physical activity seems to have expanded even further. For example, the current Australian physical activity recommendations systematically connect recommendations for physical activity and sedentary behavior for all age groups and also include advice on breaking up long periods of sitting as often as possible (27). Canada has developed comprehensive 24-h guidelines for children and adolescents older than 5 years of age, which cover four types of physical activity: moderate-to-vigorous, light, sedentary behavior and, probably most surprisingly, sleep (28). Given this dramatic expansion of the concept, one could argue that, from a sociological perspective, current physical activity recommendations have become liquid $(13,14)$, that is, they have begun to seep into every aspect of people's lives.

\section{Trend 2: diversifying target groups - from bealthy adults to everybody}

At the same pace the concept of physical activity has become liquid, the population groups targeted by these recommendations have diversified. While early Type I documents contained exercise recommendations for healthy adults only (23), later documents became more inclusive. Pate et al. also started this development by addressing all adults in general (19), but their recommendations were subsequently modified for specific target groups: children and adolescents were addressed first (29). After that, it took more than 10 years for the first recommendations specifically targeting older people to be published (30), and to this day, most recommendations continue to focus on adults (31).

Newer Type I documents, however, seem to move beyond the three 'classic' target groups (children/ adolescents, adults, older people). For example, the German recommendations (32) also include a separate chapter on adults with a chronic disease. In addition, the recommendations distinguish between 
infants and toddlers ( $0-3$ years), preschool children (4-6 years), primary school children (6-11 years) and adolescents (12-18 years).

In the future, the diversification of target groups might even increase. For example, a new infographic recently published by Public Health England specifically targets persons with disabilities (33). This diversification of target groups may be explained, on the one hand, by our more in-depth understanding of the specific demands and benefits of physical activity for different population groups (34). On the other hand, it may also reflect political demands, for example, regarding the inclusion and equality of persons with disabilities (35).

\section{Trend 3: globalizing physical activity promotion}

Compared with trends 1 and 2, the development of political documents that either describe which physical activity interventions should be conducted (Type II documents) or attempt to formulate policies for the promotion of physical activity (Type III documents) is more difficult to capture.

In its early days, physical activity promotion was something only a few nations engaged in. In addition to the United States (25), Finland has a long policy history of physical activity promotion. Developments in the sports sector began as early as the mid-1960s. The first Sports Act (1980) put a focus on sports for all for fitness and health, and the national plan to develop health education (1983) included physical activity as one of the habits to be promoted (36).

Gradually though, the topic of physical activity promotion reached the public health agenda in many other nations and on the international stage. One of the earliest international Type II documents for physical activity promotion was the joint position statement by the WHO and the International Society and Federation of Cardiology (37). It highlighted the importance of physical inactivity as an underestimated risk factor for coronary heart disease and called for including physical activity promotion in prevention policies, particularly in industrialized countries with a high proportion of sedentary jobs.

The document marked the commencement of international organizations being involved in the field of physical activity promotion. Subsequent milestones included the WHO Global Strategy on Diet, Physical Activity and Health (7), which is based both on the notion of HEPA and the involvement of multiple policy sectors and actors, and the EU Physical Activity Guidelines (8), which recommended policy actions supporting HEPA for a number of sectors. The publication of the Physical Activity Strategy for the WHO European Region 2016-2025 (9) and the WHO Global Action Plan on Physical Activity 20182030 (3) can be seen as the final steps in this development - physical activity promotion reached the global stage in 2018.

\section{Trend 4: emancipating physical activity promotion - from add-on to stand-alone topic}

The fourth trend is partially intertwined with the third and refers to the gradual emergence of physical activity promotion as a stand-alone public health topic. In earlier Type II and Type III documents, physical activity was often reduced to as a 'junior partner' to nutrition. Examples include the WHO Global Strategy (7) and the WHO European Action Plan for Food and Nutrition Policy 2007-2012 (38), but also national policy documents such as the German national initiative to promote healthy diets and physical activity (6). Arguably, this integration of health topics decreased the political visibility and autonomy of physical activity.

The EU Guidelines (8) are a noteworthy milestone in the development toward physical activity promotion as a topic in its own right as they focus exclusively on physical activity. The WHO European Region also played a leading role with its 2013 Vienna Declaration that, for the first time, mandated the development of a stand-alone physical activity strategy for the region alongside an updated action plan on nutrition (39). The result was the Physical Activity Strategy for the WHO European Region 2016-2025 (9).

Interestingly, such emancipation of physical activity as a public health topic in its own right has led to new dependencies, as a growing number of sectors have been included in recent efforts. For example, the implementation of freely accessible, regular, mass participation initiatives in public spaces mentioned in the new WHO Global Action Plan (3) may be initiated by various sectors, including sport, health, parks, and recreation or even the social sector. Again, one might argue that physical 
activity promotion has entered a state of complexity, frequent change, and blurred boundaries - in short: a liquid state.

\section{Trend 5: taking the lead in physical activity promotion - conflicts between sport, health, and other sectors}

The final 'trend' could also be considered a constant rather than a development: while more and more sectors seem to be engaging in physical activity promotion, which sector should take the lead appears to be unresolved.

From the outset, Type II documents resulted in calls to step up public efforts to promote exercise among adults. With the US Surgeon General's report in 1979, the health sector (cardiology) took the lead in calling for increased efforts to promote exercise (25). In Finland, by contrast, the earliest efforts to promote physical activity were made by the sports sector (36).

The situation at the national level remains complex to this day. In some EU member states, for example, the health sector leads physical activity promotion (e.g., Croatia, Denmark, and UK), while in others, this role is taken by the sports sector (e.g., Austria, Finland, and Poland). There are also cases of high-level coordination between the two sectors: in Germany, the Federal Ministry of Health is responsible for physical activity but closely collaborates with the German Olympic Sports Federation in most matters of physical activity promotion.

At the international level, current WHO documents (by default written from a health perspective) favor the health sector but emphasize the strong role of other sectors $(3,9)$. The EU Council Recommendation underlines the importance of both the health and the sports sectors (21). In this context, it is interesting to note that this policy document, while championing the concept of HEPA over a narrow sport or exercise focus, originated from the Sport Unit of the European Commission.

In order to explain this diversity, it is important to understand the key strengths and weaknesses of both sectors. When it comes to physical activity promotion, the sports sector faces one key dilemma: sport per se is not healthy. Studies have demonstrated convincingly that certain sports (or exercises) can produce specific health benefits (40). But at the same time, it has been demonstrated that there is no evidence base for the health effects of many other sports (41) and that competitive sport might even be detrimental to athletes' health (42). To deal with this dilemma, the sports sector has stepped up efforts to market grassroots sport as the perfect tool to promote physical activity. By doing so, however, it encountered the dilemma of balancing objectives (and resources) of sports federations between competitive sport and grassroots sport.

The health sector faces another dilemma: it is in need of a partner to promote physical activity, since it has limited resources to do so on its own. Physical activity counseling by medical staff can be operated by the health sector independently but achieves only modest success rates (43). Sports facilities are important for many other measures, but they are usually owned and administered by the sports sector. Under these circumstances, the health sector may either convince the sports sector to engage in a cooperation (e.g., by promising to channel funds from the health sector to the sports sector) or explore its chances with other sectors such as urban planning (under the label 'active transport').

\section{Discussion}

Bauman's concept of liquid modernity has guided our analysis and reflection about the different trends. We believe the investigated documents clearly indicate that today's physical activity promotion is in a state of constant change, is characterized by the ongoing expansion of basic concepts, spheres affected, and sectors involved, and suffers from uncertainties about the boundaries between physical activity vis-à-vis other areas of health promotion and from leadership conflicts between sectors. We think that it is safe to say that the current state of physical activity promotion can be adequately described as liquid in Bauman's sense.

But is this new state preferable to the old, more solid character of physical activity promotion? As indicated, each trend comes with a set of improvements and opportunities, but also with specific drawbacks and risks: expanding the concept of physical activity (Trend 1 ) to an expanding range of target groups (Trend 2) reflects the improved evidence-base of physical activity and helps to better grasp all facets of this complex phenomenon. However, translating this evidence into 
recommendations for individuals means linking physical activity to an increasingly wide array of behaviors (such as sitting, eating, and sleeping for different target groups), increasing the risk of confusing potential end users. At the policy level, globalizing efforts to counteract physical inactivity (Trend 3) as a stand-alone topic (Trend 4) has helped put the issue into the focus of relevant international organizations, thus greatly improving its visibility. On the downside, this may lead to generic one-sizefits-all solutions that will require the coordination of multiple sectors and dealing with emerging new dependencies and complexities. Against this backdrop, the ongoing conflict between different sectors involved in physical activity promotion (Trend 5) may take important resources away from actual health promotion efforts.

A closer reflection about the implications of our analysis leads us to three more general questions that we would like to put forward for further consideration.

\section{Are there three ages of physical activity promotion?}

Taking the logic of the liquid age even further, one might be tempted to state that physical activity is actually entering the third age in its development, which could be roughly sketched out as follows:

- A first age, characterized by a focus on exercise and fitness, national level actions, and its integration into general efforts to combat noncommunicable diseases (the 'Exercise and Fitness Age').

- A second age, characterized by the emergence of the HEPA concept, the internationalization of actions, and a close connection with healthy nutrition (the 'HEPA Age').

- A third age, characterized by recommendations becoming all-encompassing, and promotion efforts being global, seeping into all sectors, and emancipated from other public health topics (the 'Liquid Age').

Such a simple typology is tempting but also misleading to a certain degree. For one thing, it is impossible to mark exactly when one age should have ended and the next one started. Nations have entered different ages sooner or later than others: one might argue that Finland has been in the third age since the 1980s, while other nations are still waiting for the second age to arrive. Secondly, reality is much messier than a three-age distinction might suggest. For example, the 'linear' ascent of physical activity from a national to a global health topic (Trend 3) upon closer inspection may not be quite so linear: national and international documents are often developed in parallel, and national governments play a key role in developing international guidelines, recommendations, and policies. In conclusion, while we maintain that the current state of physical activity promotion is transitional, we are not sure whether there is a clear progression of developmental stages, and it may be up to other researchers to further explore this possibility.

\section{Type I, Type II, and Type III documents: how} are they connected?

A reoccurring theme in tracking the five trends is the relationship between physical activity recommendations (Type I documents), good practice guides for interventions to promote physical activity (Type II documents), and documents that contain actual policies to increase physical activity (Type III documents). As in the case of the 'three ages,' it is tempting to suggest a linear causality between new recommendations (e.g., HEPA) that stimulate research into new interventions (e.g., active living), which ultimately scale up into new policies (creating physical activity-friendly environments).

However, such linear thinking is based on the implicit assumption that the people who develop Type I documents are different from those developing Type II or -III documents.

Again, reality is likely to be much more complex, and there is probably a considerable overlap between these three groups. In addition, some Type II or -III documents were well ahead of their time and preceded the Type I documents on which they should have been based according to a linear logic: for example, the Finnish 'health in all' policy approaches of the 1980s (36) were already based on a comparatively broad concept of physical activity at a time when ACSM recommendations were still firmly grounded in the concept of exercise (24). Again, more research would be needed to untangle 
the complex relationship of the three major types of physical activity promotion documents.

\section{From liquid to 'dissolved'? What does the future hold for physical activity promotion?}

A final, even more daring question that arises from the analysis of the five major trends pertains to the future of physical activity promotion after the current liquid age. On the one hand, it appears as if the topic is now at its strongest ever, with serious efforts being made to combat physical inactivity by the $\mathrm{WHO}$, the EU, other supranational organizations as well as many nation states around the world. Driven by ever increasing obesity and noncommunicable disease rates straining the healthcare systems in many nations (44), one might hope that even more political will and financial resources will be invested in combating physical inactivity. Some advocates such as the State Government of Victoria (Australia) already envision physical activity promotion becoming as central to public health as tobacco control ('sitting is the new smoking').

In a less optimistic scenario, however, physical activity may continue to 'liquefy,' under the threat of getting lost in a health promotion landscape where every part of life is considered to be linked to physical activity, and where all policy sectors are considered relevant to counteracting inactivity. In such a scenario, physical activity could be literally 'dissolved' as a distinct public health issue in favor of more general efforts to promote healthy lifestyles.

Apart from theoretical implications, our results may have direct practical consequences for researchers, practitioners, and policymakers. In particular, it will be necessary to strike a balance between two poles: including a maximum number of individuals, population groups, sectors, and even countries in forthcoming physical activity promotion efforts at one end; and more focused approaches with a more limited scope but clearer messages and a potentially higher impact at the other. Eventually, the choice faced by physical activity promoters may be a strategic rather than an academic one: will it serve their cause better to embed physical activity in as many areas of people's lives as possible, or will it be advisable to give the issue a clear edge at the expense of limiting efforts to a few select sectors?

\section{Declaration of conflicting interests}

The authors declare that there is no conflict of interest.

\section{Funding}

The authors received no financial support for the research, authorship, and/or publication of this article.

\section{ORCID iD}

Sven Messing (iD) https://orcid.org/0000-0002-9645-4079

\section{References}

1. Lee IM, Shiroma EJ, Lobelo F, Puska P, Blair SN, Katzmarzyk PT. Effect of physical inactivity on major non-communicable diseases worldwide: an analysis of burden of disease and life expectancy. Lancet. 2012; 380: 219-229.

2. Guthold R, Stevens GA, Riley LM, Bull FC. Worldwide trends in insufficient physical activity from 2001 to 2016: a pooled analysis of 358 population-based surveys with 1.9 million participants. Lancet. 2018; 6: e1077-e1086.

3. WHO. Global Action Plan on Physical Activity 2018 2030: More Active People for a Healthier World. Geneva: WHO; 2018.

4. Piercy KL, Troiano RP, Ballard RM, Carlson SA, Fulton JE, Galuska DA, et al. The physical activity guidelines for Americans. JAMA. 2018; 320:20202028.

5. Leon L, Pesce C. From delivery to adoption of physical activity guidelines: realist synthesis. Int J Environ Res Public Health. 2017;14.

6. Bundesministerium für Ernährung, Landwirtschaft und Verbraucherschutz, Bundesministerium für Gesundheit, IN FORM [Internet]. Nationaler Aktionsplan zur Prävention von Fehlernährung, Bewegungsmangel, Übergewicht und damit zusammenhängenden Krankheiten [cited 2019 February 18]. Available from: https://www.bmel. de/SharedDocs/Downloads/Broschueren/Aktions planINFORM.pdf. German.

7. WHO. Global Strategy on Diet, Physical Activity and Health. Geneva: WHO; 2004.

8. European Commission. EU Physical Activity Guidelines. Recommended Policy Actions in Support of Health-Enhancing Physical Activity. Brussels: European Commission; 2008.

9. WHO Regional Office for Europe. Physical Activity Strategy for the WHO European Region 2016-2025. Vilnius: WHO Regional Committee for Europe; 2015.

10. Cameron C, Craig CL, Bull FC, Bauman A. Canada's physical activity guides: has their release had an impact? Can J Public Health. 2007; 98(Suppl 2): S161-S169.

11. Rütten A, Abu-Omar K, Gelius P, Schow D. Physical inactivity as a policy problem: applying a concept from policy analysis to a public health issue. Health Res Policy Syst. 2013; 11. 
12. Blair SN, LaMonte MJ, Nichaman MZ. The evolution of physical activity recommendations: how much is enough? Am J Clin Nutr. 2004; 79: 913-920.

13. Bauman Z. Liquid Modernity. Cambridge; Oxford; Boston; New York: Polity Press; 2000.

14. Bauman Z. Liquid Life. Cambridge; Oxford; Boston; New York: Polity Press; 2005.

15. Glassner B. Fitness and the postmodern self. J Health Soc Behav. 1989; 30: 180-191.

16. Harvey D. The Condition of Postmodernity. Malden; Oxford; Victoria: Blackwell Publishing; 1990.

17. Giddens A. The Consequences of Modernity. Stanford: Stanford University Press; 1990.

18. Rütten A, Schow D, Breda J, Galea G, Kahlmeier S, Oppert JM, et al. Three types of scientific evidence to inform physical activity policy: results from a comparative scoping review. Int J Public Health. 2016; 61: 553-563.

19. Pate RR, Pratt M, Blair S, Haskell WL, Macera CL, Bouchard C, et al. Physical activity and public health. A recommendation from the Centers for Disease Control and Prevention and the American College of Sports Medicine. JAMA. 1995; 273: 402-407.

20. WHO. Interventions on Diet and Physical Activity: What Works: Summary Report. Geneva: WHO; 2009.

21. Council of the European Union. Council Recommendation on Promoting Health-enhancing Physical Activity Across Sectors. Brussels: Council of the European Union; 2013.

22. ACSM. Guidelines for Graded Exercise Testing and Exercise Prescription. Philadelphia, PA: Lea \& Febiger; 1975.

23. ACSM. American College of Sports Medicine position statement on the recommended quantity and quality of exercise for developing and maintaining fitness in healthy adults. Med Sci Sports. 1978; 10: 7-10.

24. Haskell WL. Evolution of physical activity recommendations. In: Lee I-M (ed.) Epidemiologic Methods in Physical Activity Studies. Oxford: Oxford University Press; 2011, pp. 283-301.

25. U.S. Department of Health, Education, and Welfare. Healthy People. The Surgeon General's Report On Health Promotion And Disease Prevention 1979. Washington, DC: U.S. Department of Health, Education and Welfare; 1979.

26. Foster C. Guidelines for Health-Enhancing Physical Activity Promotion Programmes. Oxford: British Heart Foundation Health Promotion Research Group, University of Oxford; 2000.

27. Australian Government Department of Health [Internet]. Australia's Physical Activity and Sedentary Behaviour Guidelines [cited 2019 February 18]. Available from: http://www.health.gov.au/internet/ main/publishing.nsf/Content/health-pubhlth-strategphys-act-guidelines/.

28. CHEO Research Institute, The Conference Board of Canada, CSEP, Public Health Agency of Canada, ParticipACTION [Internet]. Canadian 24-HourMovement Guidelines for Children and Youth [cited
2019 February 18]. Available from: http://www.csep. $\mathrm{ca} / \mathrm{CMFiles/Guidelines/24hrGlines/Canadian24Hour}$ MovementGuidelines2016.pdf.

29. Sallis JF, Patrick K. Physical activity guidelines for adolescents: consensus statement. Pediatr Exerc Sci. 1994; 6: 302-314.

30. Nelson ME, Rejeski WJ, Blair SN, Duncan PW, Judge JO, King AC, et al. Physical activity and public health in older adults: recommendation from the American College of Sports Medicine and the American Heart Association. Med Sci Sports Exerc. 2007; 39: 14351445.

31. Kahlmeier S, Wijnhoven TMA, Alpiger P, Schweizer C, Breda J, Martin BW. National physical activity recommendations: systematic overview and analysis of the situation in European countries. BMC Public Health. 2015; 15: 133.

32. Rütten A, Pfeifer K. National Recommendations for Physical Activity and Physical Activity Promotion. Erlangen: FAU University Press; 2016.

33. Public Health England [Internet]. New support launched for disabled adults to improve health 2018 [cited 2018 November 14]. Available from: https:// www.gov.uk/government/news/new-supportlaunched-for-disabled-adults-to-improve-health.

34. Bartlo P, Klein PJ. Physical activity benefits and needs in adults with intellectual disabilities: systematic review of the literature. Am J Intellect Dev Disabil. 2011; 116: 220-232.

35. United Nations. Convention on the Rights of Persons with Disabilities. New York: United Nations Headquarters; 2006.

36. Vuori I, Lankenau B, Pratt M. Physical activity policy and program development: the experience in Finland. Public Health Rep. 2004; 119: 331-345.

37. Bijnen FCH, Caspersen CJ, Mosterd WL. Physical inactivity as a risk factor for coronary heart disease: a WHO and International Society and Federation of Cardiology position statement. Bull World Health Organ. 1994; 72: 1-4.

38. WHO Regional Office for Europe. WHO European Action Plan for Food and Nutrition Policy 20072012. Copenhagen: WHO Regional Office for Europe; 2008.

39. WHO Regional Office for Europe. Vienna Declaration on Nutrition and Noncommunicable Diseases in the Context of Health 2020. Vienna: WHO Ministerial Conference; 2013.

40. Junior LCH, Pillay JD, Van Mechelen W, Verhagen E. Meta-analyses of the effects of habitual running on indices of health in physically inactive adults. Sports Med. 2015; 45: 1455-1468.

41. Oja P, Titze S, Kokko S, Kujala UM, Heinonen A, Kelly P, et al. Health benefits of different sport disciplines for adults: systematic review of observational and intervention studies with metaanalyses. Br J Sports Med. 2015;49.

42. Street EJ, Jacobsen KH. Prevalence of sports injuries among 13- to 15-year-old students in 25 low- and middle-income countries. J Comm Health. 2017; 42: 295-302. 
43. Campbell F, Holmes M, Everson-Hock E, Davis S, Woods HB, Anokye N, et al. A systematic review and economic evaluation of exercise referral schemes in primary care: a short report. Health Technol Assess. 2015; 19: 1-110.
44. Cho NH, Shaw JE, Karuranga S, Huang Y, da Rocha Fernandes JD, Ohlrogge AW, et al. IDF Diabetes Atlas: global estimates of diabetes prevalence for 2017 and projections for 2045. Diabetes Res Clin Pract. 2018; 138: 271-281. 